\title{
O LOCKDOWN DA COVID-19 E A BUSCA POR UMA VIDA ACADÊMICA NUMA UNIVERSIDADE PÚBLICA EM 2021
}

\section{THE LOCKDOWN OF COVID-19 AND THE SEARCH FOR ACADEMIC LIFE IN A PUBLIC UNIVERSITY IN 2021}

\author{
Aliana Alves de Souza \\ alasouza@uneb.br \\ Mestra em Gestão e Tecnologias Aplicadas à Educação \\ Universidade do Estado da Bahia (UNEB), Brasil \\ Lattes http://lattes.cnpq.br/7076222984372863

\begin{abstract}
Marcia Margarida Nunes da Silva Martins
mmmartins@uneb.br

Mestra em Mestra em Segurança Pública Justiça e Cidadania

Universidade do Estado da Bahia (UNEB), Brasil Lattes http://lattes.cnpq.br/2691725866838764
\end{abstract} \\ Leonardo Machado Nascimento \\ lmnascimento@uneb.br \\ Doutorando em Ciências Sociais \\ Universidade do Estado da Bahia (UNEB), Brasil \\ Lattes http://lattes.cnpq.br/2976973353348137 \\ Sônia Maria da Conceição Pinto \\ spinto@uneb.br \\ Pós-doutora em Mídia e Conhecimento \\ Universidade do Estado da Bahia (UNEB), Brasil \\ Lattes http://lattes.cnpq.br/5984421453134421 \\ Silvar Ferreira Ribeiro \\ sfribeiro@uneb.br \\ Pós-doutor em Mídia e Conhecimento \\ Universidade do Estado da Bahia (UNEB), Brasil \\ Lattes http://lattes.cnpq.br/0130140163490918
}

\section{Resumo:}

O isolamento social imposto pelas autoridades governamentais em muitas regiões do planeta, mas especialmente, no estado da Bahia e no município de Camaçari, decorrente das estratégias de combate à disseminação da Covid 19, doença provocada pelo corona vírus, determinou a suspensão de atividades presenciais e levou as universidades a buscarem alternativas para a manutenção do seu funcionamento, assim como aconteceu com diversos outros setores da 
vida em sociedade. No campus 19 da Universidade do Estado da Bahia, cujas aulas foram interrompidas no mês de março de 2020, um grupo de trabalho composto por representantes dos diversos segmentos da comunidade acadêmica, elaborou uma proposta de trabalho remoto, que se dividiu em etapas, iniciando com um seminário on-line e estendendo-se para a criação de comunidades virtuais de aprendizagem, com o objetivo de promover o uso intensivo de tecnologias digitais da informação e comunicação, mobilizando professores, estudantes e servidores técnico administrativos para reunirem esforços e realizarem conferencias, seminários, oficinas remotas, preparando a todos para um novo momento que viria no futuro, com a confirmação de que o retorno às aulas presenciais continua incerto e imprevisível, vez que ainda não se sabe até quando a situação permanecerá ou mesmo se algum dia poderemos retomar as nossas atividades da forma como fazíamos antes.

Palavras-chave: Educação, Tecnologias digitais da informação e comunicação, Ensino remoto.

\begin{abstract}
:
The social isolation imposed by government authorities in many regions of the planet, but especially in the state of Bahia and in the municipality of Camaçari, due to strategies to combat the spread of Covid 19, a disease caused by the corona virus, determined the suspension of face-to-face activities and led universities to look for alternatives to maintain their functioning, as happened with several other sectors of life in society. On campus 19 of the University of the State of Bahia, whose classes were interrupted in March 2020, a working group composed of representatives of the various segments of the academic community, prepared a proposal for remote work, which was divided into stages, starting with an online seminar and extending to the creation of virtual learning communities, with the objective of promoting the intensive use of digital information and communication technologies, mobilizing professors, students and administrative technical servers to join efforts and hold conferences, seminars, remote workshops, preparing everyone for a new moment that would come in the future, with the confirmation that the return to face-to-face classes remains uncertain and unpredictable, since it is still unknown how long the situation will remain or even if we will ever be able to resume our activities the way we did before.
\end{abstract}

Keywords: Education, Information and communication technologies, Remote education.

Os autores e autoras deste relato, professores e professoras do Departamento de Ciências Humanas e Tecnologias (DCHT XIX) da Universidade do Estado da Bahia (UNEB), Campus da cidade de Camaçari, apresentam uma experiência, realizada no decorrer do ano de 2020, para registar um momento de mudanças profundas nas nossas vidas pessoais e profissionais, descrevendo as ações desenvolvidas pela sua comunidade acadêmica, com a participação direta e intensiva de estudantes, servidores técnico-administrativos e docentes para enfrentar e superar as agruras desta catástrofe mundial conhecida como a pandemia da Covid 19, provocada pela disseminação do corona Vírus. 
No dia onze de março do ano de 2020, a OMS (Organização Mundial da Saúde) declarou que o mundo entrou em estado de pandemia, pouco mais de três meses, depois de constatado o primeiro caso da infecção, na cidade de Wuhan, na China.

Uma pandemia, segundo Vick (2020), é a disseminação mundial de uma nova doença para a qual as pessoas não têm imunidade, segundo definição da OMS. Ainda segundo a autora, a propagação acontece de forma inesperada e, muitas vezes, descontrolada, cruzando fronteiras e atingindo um grande número de pessoas ao mesmo tempo. Os agentes transmissores do Corona Vírus, causador da Covid19, são as pessoas de todas os matizes étnicos, classe social, idade, etc., potencializados pela sua intensa circulação por todo o globo terrestre, embalados pela economia transnacionalizada, que caracteriza os nossos dias, pelo turismo, pelas viagens de negócios, viabilizadas pelo intenso tráfego aéreo, terrestre e marítimo, através de modernos equipamentos que encurtam a distância e o tempo de deslocamento.

Em números atualizados, de dezembro de 2020, quando da escrita deste relatório, o mundo já registrava mais de 31 milhões de casos de infecção confirmados e mais de 970.000 mortes. O Brasil já contabiliza, aproximadamente, 6.500 .000 casos confirmados e 175.000 óbitos.

Quase um ano depois, às vésperas da publicação deste texto, a situação se encontra muito pior, com o registro de 103.377.424 casos da doença, 2.236.454 mortes no mundo. No Brasil, já se somam 9.229.322 casos de infecção e 225.099 óbitos.

O mais preocupante é que, apesar de já terem sido desenvolvidas e aplicadas vacinas que visam proteger a população mundial do avanço da doença, os casos de infecções de perdas de vidas ainda se proliferam e estão longe de poderem ser considerados controlados.

Diante desta emergência global o Governo do Estado da Bahia publicou em diário oficial, no dia 16 de março de 2020, o decreto n. ${ }^{\circ} 19.529$ que regulamentou medidas temporárias para o enfrentamento da emergência de saúde pública decorrente do corona vírus, determinando o isolamento social, a quarentena e um conjunto de medidas visando a contenção da transmissão em larga escala da doença, tendo em vista a sua velocidade de contágio, a falta de tratamento conhecido e a escassez de leitos hospitalares, notadamente, unidades de tratamento intensivo, aparelhadas para garantir e sobrevivência de pessoas infectadas.

Fechadas em suas casas, impedidas de realizarem as atividades da sua vida diária, tais como ir à escola, à universidade, ao trabalho e aos locais públicos onde exerciam as suas atividades de lazer, esporte e interações sociais as mais diversas, as pessoas, passado o impacto inicial, passaram, segundo 
Almeida et. al. (2020) a buscar novas formas de relacionamento, e trabalho e de estudos, reinventando hábitos e buscando de forma rápida dar respostas inteligentes às incertezas do momento.

No Departamento de Ciências Humanas e Tecnologias - DCHT XIX da Universidade do Estado da Bahia, Campus XIX - Camaçari, após os primeiros quarenta e cinco dias decorridos desde a paralização das atividades acadêmicas, a comunidade se mobilizou em busca de alguma alternativa para não perder os vínculos com as suas atividades, projetos, aspirações e relações entre os seus membros. Foi criado então, através do Ato n. ${ }^{\circ}$ 137/2020, de 20 de abril de 2020, com o objetivo de "discutir e apresentar propostas para a utilização de tecnologias on-line nas atividades acadêmicas durante a pandemia COVID-19, no âmbito do Campus XIX, um Grupo de Trabalho Interdisciplinar composto por estudantes, servidores técnico-administrativos e professores dos cursos de Bacharelado em Ciências Contábeis e Direito, que realizou seus trabalhos de forma remota, fazendo reuniões semanais. Como estratégia de organização dos trabalhos foram criadas duas comissões temáticas, uma pedagógica e outra tecnológica, as quais fizeram reuniões específicas, sobre suas áreas para trazer ideias e sugestões a serem debatidas no GT, nas reuniões gerais.

Os resultados dos trabalhos do GT Interdisciplinar forneceram ao DCHT XIX e seus respectivos colegiados de Ciências Contábeis e Direito, subsídios para planejar e realizar as atividades complementares, visando atingir o objetivo de viabilizar as atividades acadêmicas, para que as mesmas não permanecessem paralisadas durante o período de isolamento social, decorrentes dos efeitos da pandemia. Além disso, sua implementação possibilitou o estudo de soluções pedagógicas e tecnológicas para serem aproveitadas no futuro, quando forem reiniciadas as atividades regulares de graduação e de pós-graduação no âmbito do Departamento, depois desse período.

As atividades das comissões, pedagógica e tecnológica, resultados de estudos e discussões, estão descritas abaixo e deram subsídios para a realização do I Seminário Interdisciplinar On-line do DCHT XIX e após a realização e avaliação do Seminário, motivou a criação das Comunidades On-line de Aprendizagem, que se encontram em fase de estruturação.

\section{1 - Comissão Temática Tecnológica}

Foram pesquisadas por essa comissão um número significativo de tecnologias digitais de informação e comunicação (TDIC), visando fazer uma reflexão sobre as mesmas, suas formas e possibilidades de uso nas atividades acadêmicas, questões relacionadas ao acesso de estudantes, professores e técnicos, tendo em vista questões como disponibilidade de equipamentos, condições de acesso, conectividade, domínio das interfaces pelos diversos usuários, custos, eficácia pedagógica.

Revista RENOVE, versão On-line, Camaçari, v.1, n.1, 2020. 
As TDIC foram apresentadas ao grupo e algumas constatações e reflexões se converteram em recomendações aqui elencadas.

\subsection{1 - Uso de tecnologias corporativas da universidade}

O GT entende que será mais acessível e menos dispendioso dar preferência às tecnologias que já estão disponíveis na universidade, tais como seus portais acadêmicos, softwares corporativos da Microsoft (Outlook, Teams, Pacote Office, etc), bancos de dados de pesquisa, tais como o Portal de Periódicos CAPES, recursos da Rede Nacional de Pesquisa (RNP), tais como conferência web, file transfer e outros, além do Ambiente Virtual de Aprendizagem (Moodle UNEB) e Sistema Gerenciador de Eventos (SGE- UNEB). Recomenda-se também a exploração das funções já disponíveis no Portal do Sistema Acadêmico (SGC-Sagres) e uso do Sistema de Bibliotecas e de seus repositórios e bancos de teses e dissertações com os quais a universidade já mantém parcerias.

Durante os trabalhos foram agendadas reuniões com o SGC Prograd e com a Gerência de Informática para consultar sobre a possibilidade da oferta de treinamentos para os usuários visando a otimização destes recursos.

Cogitou-se ainda, propor à administração central a concessão de e-mail institucional e login corporativo para todos os estudantes da universidade para permitir que os mesmos tenham acesso aos recursos, dentre estes citados, que são restritos às pessoas que fazem parte do banco de dados corporativo da instituição.

Outra possibilidade, debatida no GT foi solicitar da administração central a aquisição de tablets ou netbooks com conexão de Internet, para serem fornecidos para estudantes com matrícula ativa, que não tenham condições financeiras de adquirir equipamentos e/ou pagar provedores de Internet. Os dispositivos deverão ser devolvidos no final do curso ou em caso de trancamento de matrícula para possibilitar o uso por outros estudantes, na mesma condição.

\subsection{2 - Uso de Tecnologias não corporativas}

O GT concluiu também que outras tecnologias, além destas corporativas devam ser utilizadas nas atividades acadêmicas, visando maior aproximação com os estudantes, tendo em vista a popularidade e as questões culturais que predominam nos hábitos de acesso de muitos estudantes, professores, técnicos e da população em geral, tais como as redes sociais, os jogos online, os smartphones, podcast, aplicativos, etc., que se constituem interfaces já popularizadas e podem representar um grande potencial para seu aproveitamento nas diversas atividades acadêmicas.

Revista RENOVE, versão On-line, Camaçari, v.1, n.1, 2020. 


\section{2 - Comissão Temática Pedagógica}

A comissão temática pedagógica, considerando a oportunidade e a exigência do momento de isolamento social, bem como a situação de extrema necessidade da realização de atividades remotas, em vários setores da sociedade, especialmente no setor da educação, realizou estudos no sentido de buscar formas de viabilizar a realização das atividades acadêmicas complementares, de forma não obrigatória, considerando as dificuldades de acesso online dos estudantes.

Buscou-se, inicialmente, compreender o contexto social que vivenciamos e a sua relação com os processos de aprendizagem. Pozo (2008, p. 25) afirma que "Cada sociedade, cada cultura gera suas próprias formas de aprendizagem, sua cultura da aprendizagem". Assim, é em função da aprendizagem que adquirimos a cultura, que está totalmente incorporada de novas formas de aprendizagem. Nesse sentido, nos deparamos com o desafio de nos apropriarmos desse novo momento cultural que estamos vivenciando, com o isolamento social, e ao mesmo tempo de identificar e ou desenvolver novas formas de aprendizagem que nos ajudem a ampliar as nossas experiências, como professores ou estudantes.

Debatida a proposta da comissão no GT, conclui-se por recomendar que inovações pedagógicas sejam estudadas e implementadas, visando tornar o uso das TDIC uma oportunidade efetiva de manter e até melhorar a qualidade das atividades acadêmicas, buscando-se atuar no planejamento do ensino e da aprendizagem, usando-se de elementos norteadores da Formação em Rede, inovando-se no processo de avaliação da aprendizagem e buscando-se obter das tecnologias as suas melhores possibilidades de incluir e orientar e assistir os estudantes, bem como toda a comunidade acadêmica.

Para situar o contexto social que vivenciamos e justificar a necessidade da construção de um plano de atividades complementares, para este momento, tomamos como base as reflexões de Pozo (2018), quando discute sobre a nova cultura da aprendizagem, à aprendizagem da cultura, apresentado a seguir elementos que justificam a necessidade de refletirmos como lidar com esse momento, que nos exige novas aprendizagens:

- Cada sociedade, cada cultura cria suas próprias formas de aprendizagem, sua cultura da aprendizagem

- As atividades de aprendizagem precisam ser entendidas no contexto das demandas sociais que as geram.

- A função basilar da sociedade humana é incorporar a cultura, para que faça parte dela.

Revista RENOVE, versão On-line, Camaçari, v.1, n.1, 2020. 
- A necessidade de aprendermos uma nova cultura de aprendizagem que atenda os processos de formação e educação da sociedade atual demanda identificarmos quais são esses novos processos para nos posicionarmos criticamente.

- A sociedade atual nos impõe, continuamente, novas aprendizagens, que demandam dos professores e alunos uma relativização de conhecimentos que vai além da simples reprodução deles.

As reflexões e discussões com o grupo culminou na indicação de uma proposta de Formação em Rede, com base nos estudos de Pinto (2013), Ribeiro (2002), Pereira, Benite, C., Benite, A. (2013); Souza, Do Gaçiazzi (2009), com a definição de elementos norteadores indicados a seguir, a serem considerados nas atividades acadêmicas complementares.

1. Comunidades de Prática: $\mathrm{Na}$ Comunidade, a aprendizagem coletiva se torna o vínculo entre os membros com o passar do tempo. Wenger (2014) destaca que os membros de uma comunidade de prática se juntam para atividades coletivas e discussões, ajudam uns aos outros e compartilham informações, além de criarem um relacionamento que os permite aprender uns com os outros.

2. Educação mediada por tecnologias digitais: [...] a educação é o conjunto das ações, processos, influências e estruturas que intervêm no desenvolvimento humano de indivíduos e grupos na sua relação ativa com o meio natural e social, num determinado contexto de relações entre grupos e classes sociais. (LIBÂNEO 2000, p. 22).

3. Literacia digital: Apropriação de tecnologias digitais por professores e estudantes, com o desenvolvimento de cursos e atividades práticas.

4. Interdisciplinaridade: Para Garcia (2008, p. 364) a interdisciplinaridade, assume, nos Parâmetros Curriculares Nacionais, o status de "eixo organizador da doutrina curricular". Entretanto, para que ocorra a transição de um fazer pedagógico isolado para um trabalho intensamente integrado, é imprescindível que os envolvidos estejam abertos ao diálogo, à integração e ao constante cambio de seus conhecimentos especializados ampliando a quantidade e a qualidade de suas colaborações (PIERSON; NEVES, 2001).

5. Modalidade de educação convergente: Para Belloni, citado por Ribeiro, (2002) ...a educação no futuro é a convergência dos dois grandes paradigmas da educação de nosso século: o ensino convencional, presencial, e a educação aberta e a distância, diminuindo as diferenças metodológicas entre eles, no sentido de criar novos modelos nos quais 
metodologias e técnicas não presenciais serão cada vez mais utilizadas pelo ensino convencional, enquanto instituições especializadas em EaD tenderão a adotar atividades presenciais para abranger em seus cursos aquelas carreiras que exigem este tipo de atividade.

Essa reflexão, aqui trazida, nos convida a refletir sobre uma dúvida que tem pairado nos meios acadêmicos, acerca da modalidade de ensino que será mais adequada durante e após o isolamento social. A pergunta frequente tem sido no sentido de saber se o atual ensino presencial passará a ser ofertado na modalidade a distância ou não.

Podemos ver desde a muito, autores, estudiosos da educação já sinalizavam para uma opção intermediária, na qual a modalidade pode ser definida como convergente. Essa inovação pedagógica que tem suporte nas TDIC, pode nos ajudar a fazer uma escolha sem rótulos e diferente dos padrões estabelecidos, levando-nos a aproveitar o melhor das duas vertentes e tirando-nos o incômodo fardo de decidir qual aquele que funciona melhor, vez que os dois seriam utilizados naquilo que tem de melhor.

\subsubsection{Sistemas de Aprendizagens}

Os sistemas de aprendizagens são elementos práticos que necessariamente devem estar presentes na formação em rede, dando sustentação aos nós e vínculos construídos nos espaços de aprendizagem.

- Professores e estudantes propõem a criação de comunidades de prática, que proporcionem aprendizagens coletivas em torno de temáticas de interesse comum, com discussão de conteúdo específicos e resolução de problemas práticos, nas diversas áreas do conhecimento;

- Distanciamento da cultura de práticas presencialistas já consolidadas, com adaptações via ambientes virtuais de aprendizagem;

- Uso de interfaces tecnológicas que possibilitem a interatividade e autoria dos sujeitos, com elementos que possibilitem a comunicação síncrona e assíncrona;

- Envolvimento de várias disciplinas e conteúdo em um projeto;

- Avaliação diagnóstica dos processos de aprendizagem, com foco na inclusão dos estudantes;

- A carga horária de atividades nas comunidades de práticas pode ser aproveitada como atividade Atividades Curricular Complementar ou como carga horária de integralização do curso, na sua totalidade ou percentualmente, com análise dos professores; 
- Envolver sempre mais de um professor por atividade a proposição e desenvolvimento da proposta;

- Instituir um modelo de acompanhamento e avaliação da proposta/atividade/curso/disciplina.

Fundamentado nestas propostas do GT Interdisciplinar foi realizado no período de 10 a 15 de julho de 2020 o I Seminário Interdisciplinar On-line da UNEB - DCHT - Campus XIX < https://youtu.be/HtuLFM7bCm4>, reuniu 11 Web Conferências, 4 Oficinas e 10 Seminários Temáticos, contando com 600 inscrições e a participação de professores do Departamento de Camaçari e outros departamentos da Universidade, convidados externos, de outras instituições universitárias, além de ter sido transmitido em canal aberto no Youtube, criado exclusivamente para este fim, que já conta com mais de setecentas inscrições e sete mil e quinhentas visualizações, passando a reunir outros eventos realizados pelos docentes, grupos de pesquisa e estudantes do DCHT XIX. Vale ressaltar que todos estes eventos realizados estão disponíveis para acesso no endereço Canal do DCHT XIX - UNEB Camaçari - Bahia - Brasil.

Após a realização do I Seminário On-line, conforme proposta do GT Interdisciplinar, os trabalhos tiveram continuidade, outros atores se juntaram ao grupo, tendo sido mantidas as duas comissões, pedagógica e tecnológica, criando-se ainda a comissão de pesquisa e diagnósticos visando ampliar os campos de estudos, inicialmente previstos e dar maior apoio às ações do Departamento.

A nova proposta que surgiu neste período foi de criação de Comunidades de aprendizagem colaborativa online mediada por tecnologias: uma experiência do campus XIX, UNEB - Camaçari, na pandemia da COVID19.

Tal como a primeira atividade, esta fundamenta-se na constatação de que as tecnologias digitais têm se apresentado como ferramentas importantes para a mediação das práticas pedagógicas, impulsionando a realização de atividades educativas no período de isolamento social. No entanto, paralelo as facilidades e possibilidades de uso das tecnologias digitais no espaço educacional, identificamos o extenso fosso digital, a desigualdade social condicionada pelo acelerado avanço tecnológico, considerando que existem ainda muitas pessoas que não possuem acesso a esses elementos tecnológicos.

Seguindo com as ações do GT-Interdisciplinar, a Comissão da Área Pedagógica propõe o desenvolvimento do projeto de pesquisa e extensão "Comunidades online de aprendizagem colaborativa mediada por tecnologias digitais, do Campus XIX - UNEB/Camaçari, como espaço de negociações de significados e aprendizagens. Tem o objetivo de promover a interação entre 
professores e estudantes do Campus XIX, apoiada nas tecnologias digitais, para compartilhar preocupações, refletir sobre temas de interesse comum, construir, consolidar e difundir conhecimentos.

Surge na busca de compreender o contexto social que vivenciamos e a sua relação com os processos de aprendizagem. Pozo (2008, p. 25) afirma que "Cada sociedade, cada cultura gera suas próprias formas de aprendizagem, sua cultura da aprendizagem". Assim, é em função da aprendizagem que adquirimos a cultura, que está totalmente incorporada de novas formas de aprendizagem. Nesse sentido, nos deparamos com o desafio de nos apropriarmos desse novo momento cultural que estamos vivenciando, com o isolamento social, e ao mesmo tempo de identificar e ou desenvolver novas formas de aprendizagem que nos ajudem a ampliar as nossas experiências, como professores ou estudantes.

\section{Tecnologias digitais mediando interações sociais em comunidades online de aprendizagem colaborativa}

As tecnologias da Informação e Comunicação permitem a criação das comunidades de aprendizagem online que possibilitam novas abordagens para a organização dos modelos de informação e representação do conhecimento, além da interação entre os participantes, como também entre estes e as instituições de formação. Segundo Dias (2004), a colaboração e a interação compõem o modelo base para o desenvolvimento dos processos de formação on-line. Para o autor ainda, uma comunidade online

emerge da tipologia e qualidade das interações e processos de colaboração que ocorrem entre um dado conjunto de indivíduos e, deste modo, constitui o suporte para o desenvolvimento da partilha de interesses e objetivos na construção conjunta do conhecimento (DIAS, 2004, pag. 1)

Dias (2004) nos chama a atenção com relação a necessidade de construção de uma nova pedagogia, fundamentada na partilha e exposição de ideias entres pares, na colaboração e ação conjunta.

Apesar de não abordar o termo comunidades de aprendizagem colaborativa online, Wenger traz para discussão o conceito de comunidade de prática, destacando que na Comunidade, a aprendizagem coletiva se torna o vínculo entre os membros com o passar do tempo, está implicada com uma interação sólida, os membros precisam ser praticantes. Segundo Wenger (2014) ainda, os membros de uma comunidade de prática realizam atividades coletivas e discussões, ajudam uns aos outros e partilham informações, além de construírem um relacionamento que os permitem aprender coletivamente. Para Wenger (apud Pinto 2015, pg 14), 
uma website por si não é uma comunidade de prática, assim como ter o mesmo emprego ou o mesmo cargo, a não ser que os membros interajam e aprendam juntos. Para o autor, os estudantes de graduação de uma determinada área podem ter muito em comum, mas a não ser que eles interajam e aprendam juntos, eles não formam uma comunidade de prática.

Nesse sentido, uma comunidade de prática pode se constituir em diferentes espaços, desde que exista interação e aprendizagem coletiva, interesse mútuo. Serão utilizados blogs para publicar as comunidades ativas e promover a adesão dos interessados em participar. O blog (Figura 01) deverá ser utilizado ainda para socializar as ações e sistematizações de aprendizagens, dos significados construídos coletivamente em cada comunidade de prática. As comunidades devem funcionar a partir da compreensão proposta por Dias (2004) e Wenger (2014), descrita anteriormente neste documento.

Para abrir uma comunidade o professor deverá apresentar um resumo da temática que pretende abordar, justificando o seu interesse, informando o período da sua existência e problema que motivou a sua proposição e o objetivo.

Os encontros online ocorrerão na plataforma MS Teams, e poderão ser utilizadas ferramentas síncronas e assíncronas associadas ao uso do blog, além de outros recursos tecnológicos que sejam demandados para facilitar e enriquecer as trocas de experiências.

Figura 01 - BLOG da Comunidade

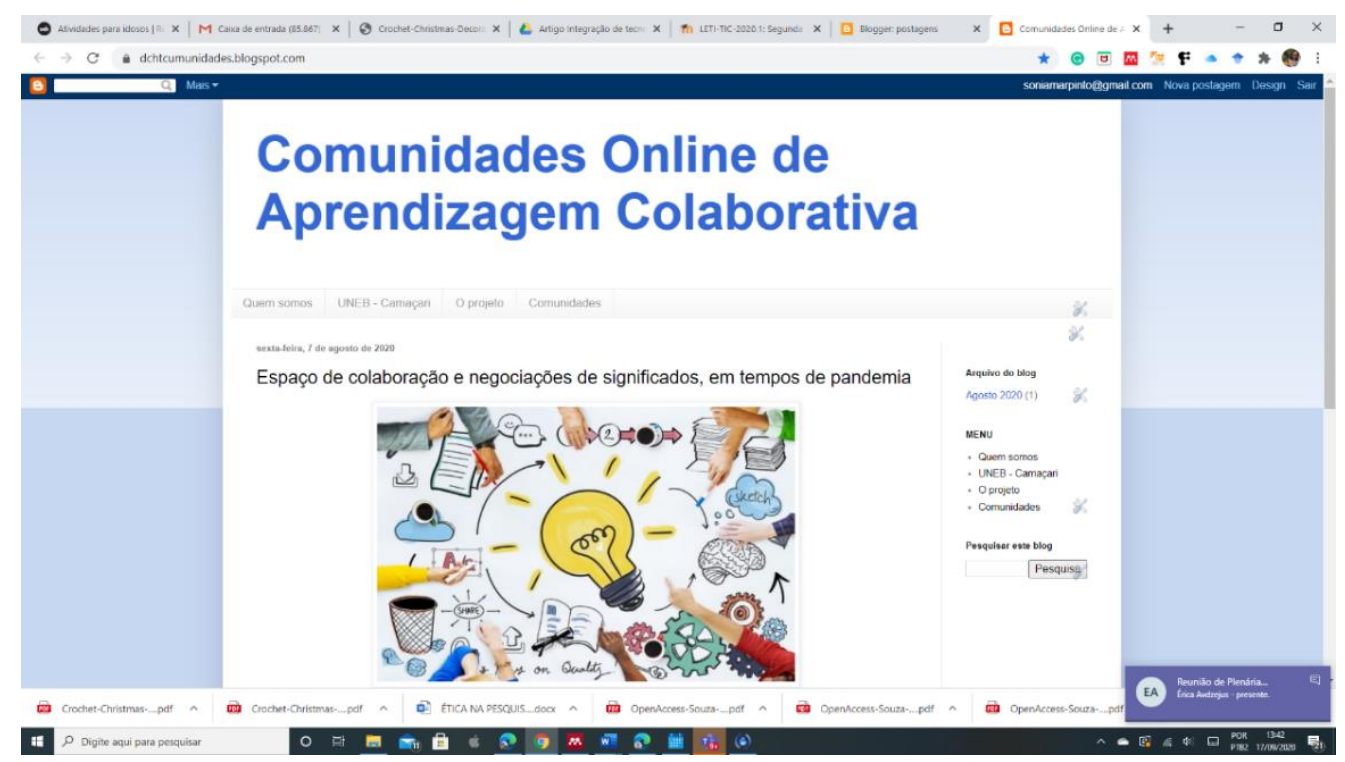

Fonte: elaborada pelos autores 
Para citar como exemplos de Comunidades de Aprendizagem em processo de estruturação, destacamse a CA Maria da Penha, voltada para investigar as alterações inseridas no processo penal e respectivas peculiaridades práticas atinentes à Lei 11.340/2006 (Lei Maria da Penha), permitindo contextualização e atualização dos estudos acadêmicos, bem como reflexão quanto à necessidade de observância das leis especiais e das práticas processuais dos futuros profissionais do direito. Assim como a CA Tecnologias Digitais da Comunicação e Informação, criada com o objetivo de apoiar ações de construção e difusão do conhecimento na docência do ensino superior com a mediação da tecnologias e busca pesquisa e propor formas de aplicação de recursos tecnológicos nos processos de ensino e aprendizagem praticados no DCHT XIX.

\section{Considerações Finais}

A criação das Comunidades On-line de Aprendizagem Colaborativa, busca identificar e mapear os significados e aprendizagens construídos nas comunidades a partir das percepções dos sujeitos envolvidos, proponentes e seus participantes. Pretende-se também identificar as suas percepções sobre o uso das tecnologias digitais na mediação das interações sociais estabelecidas nas comunidades, fomentar e apoiar a sua utilização pelos membros de toda a comunidade acadêmica, criando assim possibilidades concretas de superação das dificuldades impostas pelas medidas sociais de proteção da saúde contra a disseminação da Covid19, permitindo, no entanto que professores, técnicos e estudantes continuem atuando nos seus diversos papeis sociais, reduzindo os danos decorrentes da paralização das atividades presenciais no campus universitário.

Às vésperas do início de mais um semestre letivo, já do ano de 2021, a universidade já deliberou sobre a manutenção das atividades remotas, a esta altura mais fundamentada pelas experiências vividas naquele primeiro momento que ora relatamos, indicando a necessidade de darmos continuidade ao isolamento social, regulamentando atividade síncronas e assíncronas em todos os piares das ações universitárias de ensino, pesquisa e extensão.

O lançamento deste periódico cientifico on-line, neste momento, também se apresenta como uma das ações de enfrentamento e de superação dos desafios que estão postos, conclamando todos os segmentos que integram a vida universitária, bem como a sua comunidade do entorno, a refletir, pesquisar e divulgar suas percepções sobre esse e outros fenômenos que afetam a vida em sociedade, contribuindo assim para a sua compreensão e para a busca de soluções possíveis que possa nos fazer viver melhor a aprender continuamente.

Agradecimentos: a experiência acadêmica aqui relatada foi o resultado de um conjunto de atividades desenvolvidas por um Grupo de Trabalho aos quais os autores do texto agradecem, em reconhecimento à sua intensiva participação e contribuições, sem as quais os trabalhos não seriam concretizados: Docentes: Aliana Alves de Souza, Euzelene Rodrigues Aguiar, Jailson Braga Brandão, 
Leonardo Machado Nascimento, Karina Mizuki Dias dos Santos, Marcia Margarida Nunes da Silva Martins, Silvar Ferreira Ribeiro, Sônia Maria da Conceição Pinto, Rita Maria Brito Santos, Sergio Henrique Conceição, Gilson Alves de Santana Junior. Suely Aldir Messeder. Discentes: Adriano Pereira da Silva, Carlos Brasileiro, Rafael Bomfim Souza, Saul José Queiroz. Servidora técnicaadministrativa: Thiara Bahia Barbosa

\section{REFERÊNCIAS}

ALMEIDA, FERNANDO JOSÉ DE; ALMEIDA, MARIA ELIZABETH B. DE; SILVA, M. DA G. M. DA. De Wuhan a Perdizes: Trajetos Educativos. 1. ed. São Paulo: [s.n.].

BELLONI, Maria Luiza. Educação a distância. Campinas - SP: Autores Associados, 1999.

RIBEIRO, Silvar Ferreira A formação de professores em exercício através da educação superior a distância - perspectivas da Universidade do Estado da Bahia - UNEB. Dissertação de mestrado. Programa de Engenharia de Produção - UFSC. Florianópolis - SC: PPGEP, 2002

WENGER, Etienne. Comunidades de práctica: Aprendizaje, significado e identidad. Cognición download desarrollo humano. Paidós, 2001.

LIBÂNEO, J. Carlos. Pedagogia e pedagogos para quê? 3. ed. São Paulo: Cortez 2000.

KNOBEL, Michele. Digital Literacies: Concepts, Policies and Practicies. New York: Peter Lang Publishing, 2008. p. 151-176.

POZO. I. Juan. Aprendizes e Mestres - A nova cultura da aprendizagem. Artmed - 2008.

PINTO, M. C. Sonia. Rede de Formação: um modelo em contextos em contextos sociais de literacias digitais. Tese de Doutorado. Programa Multi-Institucional e Multidisciplinar em Difusão do Conhecimento da UFBA - 2013.

VICK, Mariana. Pandemia: origens e impactos, da peste bubônica à covid-19. NEXO JORNAL LTDA., conforme a Lei $\mathrm{n}^{\text {o }}$ 9.610/98. Acessível em: https://www.nexojornal.com.br/explicado/2020/06/20/Pandemia-origens-e-impactos-da-pestebub\%C3\%B4nica-\%C3\%A0-covid-19. Acesso 03/12/2020. 